\title{
Pseudomonas aeruginosa em hospital da microrregião de Ouro Preto, Minas Gerais, Brasil
}

\author{
Pseudomonas aeruginosa in a hospital from the \\ microregion of Ouro Preto, Minas Gerais, Brazil
}

Recebido em: 09/06/2016

Aceito em: $12 / 102016$
Gustavo Henrique Bianco de SOUZA ${ }^{1}$, Renata Rezende MIRANDA ${ }^{1}$, Luciana de Jesus INÁCIO ${ }^{1}$, Tatiane Roquete AM PARO ${ }^{1}$, Luana Beatriz Araújo VAZ ${ }^{1}$,

Maísa Angélica Silva FERNANDES ${ }^{1}$, Bruna de Carvalho MAPA ${ }^{1}$, Luiz Fernando Medeiros TEIXEIRA ${ }^{2}$, Regina Aparecida Gomes ASSENÇO ${ }^{3}$, Maria Célia da Silva LANNA ${ }^{3}$, Alessandra Júlia Santos SILVA, Marcela Maria de Castro CAMPOS $^{5}$, Elisa Maria Pedrosa da Fonseca RIOS ${ }^{4}$

${ }^{1}$ Departamento de Farmácia, Escola de Farmácia, Universidade Federal de Ouro Preto. Campus Morro do Cruzeiro, s/n, CEP 35400-000. Ouro Preto, MG, Brasil.

${ }^{2}$ Departamento de Análises Clínicas, Escola de Farmácia, Universidade Federal de Ouro Preto. Campus Morro do Cruzeiro, s/n, CEP 35400-000. Ouro Preto,

$M G$, Brasil. ${ }^{3}$ Departamento de Ciências Biológicas, Instituto de Ciências Exatas e Biológias, Universidade Federal de Ouro Preto. Campus Morro do Cruzeiro, s/n, CEP

35400-000. Ouro Preto, MG, Brasil. ${ }^{4}$ Secretaria Municipal de Saúde, Av. Juscelino Kubitscheck, 2, Bauxita, CEP 35400-000. Ouro Preto, MG, Brasil. ${ }^{5}$ Fundação Ezequiel Dias. Rua Conde Pereira Carneiro, 80, Gameleira, CEP 30510-010. Belo Horizonte, MG, Brasil.E-mail: guhbs@yahoo.com.br

\section{ABSTRACT}

Water is the main source of transmission of micro-organisms in health centers, which can cause infections that are a serious issue for public health. The goal of this study was to evaluate the microbiological quality of water used in a hospital of the microregion of Ouro Preto, Minas Gerais, Brazil. Twelve water samples were collected at different points for the detection of total and fecal coliforms, as well as other micro-organisms; in addition, antimicrobial susceptibility tests were also performed. The bacterial species Pseudomonas aeruginosa was detected in the sample from the rinse water of clean clothes collected in the laundry's clean area and it was identified by Gram stain and automated analysis using VITEK ${ }^{\circledR}$ equipment. The strain of $P$. aeruginosa showed sensitivity to the antibiotics commonly used to treat infections induced by this bacterium, such as cephalosporins, fluoroquinolones, carbapenems and polymyxins. However, the results indicate the need for a greater attention to the process of cleaning of hospital clothing, a fact that is still neglected in Brazil.

Keywords: Pseudomonas aeruginosa; hospital infection; Hospital Laundry Service; microbiology water

\section{RESUMO}

A água representa o principal meio de transmissão de micro-organismos em centros de saúde, os quais podem causar infecções que são um grave problema de saúde pública. O objetivo desse estudo foi avaliar a qualidade microbiológica da água utilizada em um hospital da microrregião de Ouro Preto, Minas Gerais, Brasil. Foram coletadas doze amostras de água em pontos distintos para testes de detecção de coliformes totais e termotolerantes, assim como de outros microrganismos; além disso, testes de sensibilidade a antimicrobianos também foram realizados. A espécie bacteriana Pseudomonas aeruginosa foi detectada na amostra correspondente à água de enxágue de roupas limpas coletada na área limpa da lavanderia e foi identificada por coloração de Gram e análise automatizada utilizando o equipamento VITEK $^{\circledR}$. O isolado de P. aeruginosa mostrou-se sensível aos antibióticos usualmente utilizados no tratamento de 
infecções induzidas por esta bactéria, tais como cefalosporinas, fluorquinolonas, polimixinas e carbapenêmicos. Contudo, os resultados indicam a necessidade de maior atenção ao processo de higienização de roupas hospitalares, fato ainda negligenciado no Brasil.

Palavras-chave: Pseudomonas aeruginosa; infecção hospitalar; Serviço Hospitalar de Lavanderia; microbiologia da água

\section{INTRODUÇÃO}

A ocorrência de infecções hospitalares representa uma das maiores ameaças aos pacientes hospitalizados, sendo necessárias medidas para seu controle e prevenção (1). Os principais agentes etiológicos causadores de infecções hospitalares no Brasil são Staphylococcus aureus, Escherichia coli, Pseudomonas aeruginosa, Acinetobacter spp., Enterobacter spp. e Klebsiella pneumoniae (2).

Dentre as principais causas que favorecem a incidência de infecções hospitalares, destacam-se: a suscetibilidade do paciente, métodos de diagnóstico e procedimentos terapêuticos utilizados. Também contribuem para o aumento da incidência, o meio ambiente hospitalar (incluindo o ar, a água e a superfície de alvenarias e móveis), devido a representarem focos de crescimento de microrganismos. Dessa forma, o padrão de assepsia e de higiene adotado pelo hospital, também constitui um risco ao desenvolvimento de infecções (1).

No âmbito do controle de infecções em centros de saúde, a água, por estar intimamente associada a outros fatores de risco, representa o principal fator de transmissão de microrganismos. No Brasil, a qualidade da água de abastecimento público é padronizada pela Agência Nacional de Saúde do Ministério de Saúde (3), de acordo com o índice de coliformes, considerados como indicadores de contaminação fecal.

$\mathrm{Na}$ avaliação da qualidade de água de centros de saúde, além de coliformes, é importante a pesquisa de bacilos Gram-negativos não-fermentadores. Essas bactérias já foram isoladas de amostras de água e podem causar graves infecções hospitalares (4). Segundo Freitas et al. (2008), a espécie $P$. aeruginosa tem sido considerada uma das mais importantes dessa classe em função da sua resistência intrínseca a desinfetantes e aos antibióticos atualmente disponíveis (5).

No presente estudo foi avaliada a qualidade microbiológica da água utilizada em um hospital da microrregião de Ouro Preto, Minas Gerais, em relação à presença de coliformes e de outros micro-organismos.

\section{MATERIAIS E MÉTODOS}

Foram coletadas doze amostras de água $(200 \mathrm{~mL})$ em pontos distintos de um hospital da microrregião de Ouro Preto, MG, no período de maio a junho de 2012. Os pontos de coleta foram previamente selecionados com o objetivo de ser obtida uma amostra representativa do local como um todo (Tabela 1).

Amostras de cada local foram coletadas em frascos de $250 \mathrm{~mL}$ previamente esterilizados, e processadas em menos de 24h, seguindo metodologia recomendada pela American Public Health Association (6). As amostras coletas foram submetidas à pesquisa de coliformes fecais e ao teste para bastonetes Gram-negativos não fermentadores, como $P$. aeruginosa.

Tabela 1: Locais de coleta de amostras de água de um hospital da microrregião de Ouro Preto, Minas Gerais, para testes de coliformes totais e termotolerantes.

\begin{tabular}{cl} 
Amostra & \multicolumn{1}{c}{ Locais de coleta de água } \\
\hline 1 & Refeitório \\
2 & Reservatório de água 1 \\
3 & Reservatório de água 2 \\
\hline 4 & Refeitório \\
\hline 5 & Área de expurgo da lavanderia \\
6 & Quarto de paciente I \\
$\mathbf{7}$ & Quarto de paciente II \\
8 & Quarto de paciente III \\
\hline 9 & Quarto de paciente IV \\
10 & Quarto de paciente V \\
11 & Torneira da área limpa da lavanderia \\
12 & Água de enxágue final de roupa lavada
\end{tabular}

A pesquisa de coliformes totais e termotolerantes foi realizada utilizando o método de fermentação em tubos múltiplos, estabelecido pelo Standard Methods for the Examination of Water and Wastewater, adotado como referência no Brasil através da Portaria 2.914 de 12/12/2011, do Ministério da Saúde (7). 


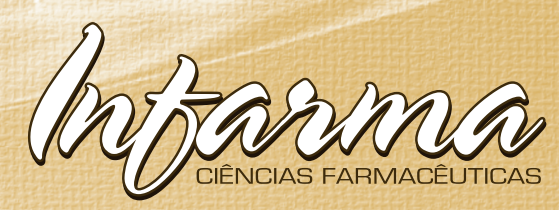

No teste de fermentação em tubos múltiplos, $1 \mathrm{~mL}$ de cada amostra foram distribuídos em tubos de ensaio contendo caldo lactosado (Himedia ${ }^{\circledR}$ ) e tubos Durham invertidos. Os tubos foram incubados em estufa bacteriológica (Fanem ${ }^{\circledR}$ modelo $002 \mathrm{CB}$ ) a $37^{\circ} \mathrm{C}$ por 24 horas, e foi considerado resultado positivo a produção de gás.

Para a deteç̧ão da presença de bastonetes Gramnegativos não fermentadores, foram utilizados tubos contendo caldo Müeller Hinton (Himedia ${ }^{\circledR}$ ). Os tubos que apresentaram turvação indicativa de crescimento microbiano foram selecionados para testes de identificação do(s) microrganismo(s) presente(s). Para tal, alíquotas de $10,0 \mu \mathrm{L}$ de cada tubo foram inoculadas em placas de Petri contento Agar nutriente (Himedia ${ }^{\circledR}$ ) e incubadas a $37{ }^{\circ} \mathrm{C}$, durante 24 horas, em estufa de cultivo bacteriológico (Fanem ${ }^{\circledR}$ modelo $002 \mathrm{CB}$ ). Ao término do tempo de incubação, foram analisadas as características das colônias. A identificação bacteriana foi realizada utilizando os testes iniciais: bacterioscopia de esfregaço corado pelo método de Gram, presença de citocromooxidase, crescimento em Agar Cetrimide e cultivo em caldo asparagina e em caldo acetamida (8).

Além destes testes iniciais, também foram realizados testes de análise automatizada com o equipamento VITEK $^{\circledR} 2$ Compact (BioMérieux, Inc.).

Os testes de identificação VITEK $^{\circledR} 2$ foram desenvolvidos de acordo com instruções do fabricante. A bactéria isolada de amostra de água do hospital da microrregião de Ouro Preto, MG, foi cultivada em ágar MacConkey por $24 \mathrm{~h} \mathrm{a} 37^{\circ} \mathrm{C}$. Após o período de incubação, foi preparada uma suspensão em salina de acordo com o tubo 0,5 da escala McFarland ( 1 x $\left.10^{8} \mathrm{UFC} / \mathrm{mL}\right)$. A análise foi realizada utilizando cartão GN Vitek ${ }^{\circledR}$ (cartão ID-GNB), específico para a identificação de bacilos Gram-negativos. Nesta análise seriada estão disponibilizados substratos liofilizados referentes a 41 provas bioquímicas (18 testes para aminopeptidades e oxidases, 18 testes de fermentação, 2 testes para descarboxilase e 2 testes mistos), incluindo: $\alpha$ - e $\beta$-galactosidase, $\beta$-N-acetil-glucosaminidase, $\quad \gamma$-glutamil-transferase, $\beta$-xilosidase, adonitol, L-arabitol, D-celobiose, D-sorbitol, D-maltose, D-manitol, urease e uso de malonato, fosfatase. Os resultados foram interpretados utilizando base de dados de identificação de bacilos Gram-negativos ID-GNB (9).

A sensibilidade dos microrganismos frente a antibióticos foi avaliada por meio do método de difusão em disco (10). Neste teste, uma suspensão bacteriana de turbidez equivalente a uma solução padrão de McFarland 0,5 foi inoculada, utilizando swab, sobre toda a super- fície de placas de Petri contendo Agar Mueller-Hinton $\left(\right.$ Prodimol $\left.^{\mathbb{}}\right)$. Em cada placa foram superpostos discos DME $^{\circledR}$ (Diagnósticos Microbiológicos Especializados) contendo os seguintes antibióticos: ampicilina/sulbactam $(20 \mu \mathrm{g})$, piperacilina/tazobactam $(110 \mu \mathrm{g})$, aztreonam $(30 \mu \mathrm{g})$, ceftazidima $(30 \mu \mathrm{g})$, cefepime $(30 \mu \mathrm{g})$, imipenem $(10 \mu \mathrm{g})$, polimixina $(300 \mu \mathrm{g})$, amicacina $(30 \mu \mathrm{g})$, ciprofloxacina $(05 \mu \mathrm{g})$, trimetoprim $(05 \mu \mathrm{g})$, tetraciclina $(30 \mu \mathrm{g})$, amoxicilina $(10 \mu \mathrm{g})$, penicilina $(10 \mu \mathrm{g})$, gentamicina $(10 \mu \mathrm{g})$ e cefalotina $(30 \mu \mathrm{g})$.

O controle da qualidade do método foi realizado com a cepa padrão de $P$. aeruginosa adquirida da coleção da American Type Culture Collection (ATCC 27853). Os halos de inibição foram medidos em $\mathrm{mm}$ e expressos como média \pm desvio padrão. De acordo com tabela fornecida pelo CLSI (11), o efeito de cada antibiótico sobre a bactéria foi classificado como sensível, intermediário ou resistente. Foram calculados a média e o desvio padrão de cada um utilizando o programa Excel $\left(\right.$ Microsoft $\left.{ }^{\mathbb{}}\right)$.

Todos os experimentos descritos, exceto as coletas, foram realizados em duplicata.

\section{RESULTADOS E DISCUSSÃO}

As amostras dos locais de 1 a 12 (Tabela 1) apresentaram resultado negativo em relação à presença de coliformes totais e termotolerantes. Por outro lado, o meio de cultura contendo a amostra coletada no local 12 (água de enxágue da roupa limpa), apresentou turvação sem produção de gás, o que levou à investigação da presença de outras espécies de microrganismos.

Macroscopicamente, as colônias obtidas a partir da amostra do local 12 apresentaram aspecto verde-azulado e odor característico (12). Esfregaços das colônias, corados pelo método de Gram foram analisados por microscopia óptica sendo evidenciada a presença de bastonetes Gram-negativos. Estes resultados sugeriram tratar-se da presença de uma bactéria do gênero Pseudomonas. Os testes realizados por meio do equipamento Vitek $^{\circledR}$ confirmaram, com $95 \%$ de probabilidade, que a bactéria isolada se tratava da espécie $P$. aeruginosa.

A partir dos resultados do antibiograma foi possível analisar a sensibilidade do isolado frente aos principais antibióticos utilizados em tratamentos de infecções. A bactéria se mostrou sensível à maioria dos antimicrobianos testados (Tabela 2). No entanto, foi resistente a cinco fármacos (ampicilina, trimetoprim, amoxicilina, penicilina e cefalotina) e mostrou-se moderadamente sensível à tetraciclina. 


\section{Anozanas}

Apesar do desenvolvimento de Programas Nacionais de Controle de Infecções Hospitalares (13), ainda tem sido pouco valorizada a importância da avaliação da qualidade microbiológica da água em centros de saúde. A água constitui o principal veículo de disseminação e transmissão de micro-organismos com potencial de patogenicidade (14). Por isso, seu controle de qualidade em centros de saúde é essencial, pois é utilizada por pacientes e profissionais da saúde para diversos fins, como: bebida; uso em procedimentos de higienização pessoal; limpeza de enfermarias, salas de cirurgia, unidades de tratamento intensivo; lavagem de roupas, preparo de refeições de pacientes submetidos a dietas especiais, e outras finalidades (14).
Neste estudo, não foram encontrados coliformes totais e termotolerantes nas amostras de água coletadas, o que mostrou que as amostras estavam de acordo com as exigências de qualidade microbiológica estabelecidas pela Portaria n. 2.914 do Ministério da Saúde. De acordo com este documento, o padrão de qualidade recomendado para as análises microbiológicas de água de uso hospitalar é o mesmo adotado para água potável. Portanto, existe uma lacuna em relação ao padrão de qualidade específico para centros de saúde pois o padrão de água potável não leva em consideração a fragilidade dos pacientes hospitalizados (14).

Tabela 2: Resultado de antibiograma para Pseudomonas aeruginosa encontrada em um hospital da microrregião de Ouro Preto, Minas Gerais

Antibiótico

Ampicilina/Sulbactam $(20 \mu \mathrm{g})$

Piperacilina/Tazobactam $(110 \mu \mathrm{g})$

Aztreonam $(30 \mu \mathrm{g})$

Ceftazidima $(30 \mu \mathrm{g})$

Cefepime $(30 \mu \mathrm{g})$

Imipenem $(10 \mu \mathrm{g})$

Polimixina $(300 \mu \mathrm{g})$

Amicacina $(30 \mu \mathrm{g})$

Ciprofloxacina $(05 \mu \mathrm{g})$

Trimetoprim $(05 \mu \mathrm{g})$

Tetraciclina $(30 \mu \mathrm{g})$

Amoxicilina $(10 \mu \mathrm{g})$

Penicilina $(10 \mu \mathrm{g})$

Gentamicina $(10 \mu \mathrm{g})$

Cefalotina $(30 \mu \mathrm{g})$
$\mathrm{HI}(\mathrm{mm})^{*}$

Resultado

0

$22,5 \pm 0,7$

$23,0 \pm 4,2$

$22,0 \pm 2,8$

$24,0 \pm 2,8$

$20,5 \pm 0,7$

$\mathrm{S}$

$13,0 \pm 1,4$

S

$23,0 \pm 0,0$

$\mathrm{S}$

$31,5 \pm 0,7$

$S$

0

R

$12,5 \pm 0,7$

I

0

R

0

$18,0 \pm 0,0$

0

R

$\mathrm{S}$

$\mathrm{S}$

$S$

S

$S$

*HI: Halo de inibição: resultado expresso como medida do halo médio $(\mathrm{mm}) \pm$ desvio padrão.

$\mathrm{S}=$ Sensível; $\mathrm{I}$ = Intermediário; $\mathrm{R}=$ Resistente.

A identificação de $P$. aeruginosa na amostra referente à água de enxágue das roupas limpas na lavanderia de um hospital da microrregião de Ouro Preto, Minas Gerais, aponta para outro aspecto relacionado ao controle de infecções hospitalares: a transmissão de microrganismos através de roupas, como cobertores, lençóis e pijamas.

O risco de transmissão de doenças por meio de roupas em hospitais tem sido negligenciado, apesar de relatos da presença de microrganismos em roupas mesmo após os processos de lavagem $(15,16)$. Além disso, estudos relataram roupas hospitalares como sendo fonte de infecções hospitalares com coliformes (17), Bacillus cereus (16), Streptococcus spp. (18) e Enterococcus spp. (19).
De acordo com Fijan e cols (2007), as espécies bacterianas P. aeruginosa, Enterococcus faecium, Staphylococcus aureus e Enterobacter aerogenes sobrevivem a processos de lavagem de roupas hospitalares, que utilizam temperatura até $60^{\circ} \mathrm{C}$ e concluíram que a temperatura é importante para a eficácia dos processos de lavagem, assim como os agentes desinfetantes utilizados, a duração dos ciclos de lavagem e a ação mecânica da máquina (15).

A presença de $P$. aeruginosa, detectada no hospital da microrregião de Ouro Preto, pode estar associada ao sabão utilizado, à superfície dos equipamentos da lavanderia ou à ineficiência do processo de lavagem das 
roupas. Estudos complementares são necessários para se concluir sobre a causa da contaminação, porém deve ser destacado que esse trabalho alerta sobre a importância da análise e do controle de todos os fatores envolvidos no processo de lavagem de roupas hospitalares.

A presença de patógenos nas roupas representa uma possibilidade de disseminação, que pode ocasionar um ciclo: os tecidos são contaminados por pacientes com infecções, os micro-organismos não são eliminados devido à ineficiência dos processos de lavagem e são transmitidos para outros pacientes.

A bacteria $P$. aeruginosa é um bastonete Gram negativo ubíquo, raramente associado a patologias em indivíduos sadios; entretanto, atualmente é considerada como uma das principais causas de infecções oportunísticas, principalmente relacionada a queimaduras, fibrose cística, bronquite crônica e infecções do trato urinário (20). Infecções sistêmicas causadas por P. aeruginosa apresentam mortalidade de até $70 \%$ em pacientes imunocomprometidos devido a doenças graves, idosos e pacientes submetidos a tratamentos com corticosteróides ou agentes imunossupressivos (21).

Este microrganismo é responsável pela formação de biofilme, caracterizado como sendo um conjunto de células microbianas envolvidas em uma matriz polimérica extracelular, aderidas a superfícies bióticas ou abióticas (22). Quando a formação de biofilme ocorre em cateteres, implantes, lentes de contato e próteses, causa graves infecções. Este fato é considerado como sendo um importante fator no desenvolvimento e persistência de contaminações em centros de saúde, indutoras de doenças infecciosas (23).

Em relação ao perfil de sensibilidade da bactéria identificada, (Tabela 2), o mesmo é explicado pela resistência intrínseca que a $P$. aeruginosa apresenta a cinco dos quinze fármacos testados, sendo os $\beta$-lactâmicos (ampicilina, amoxicilina, penicilina e cefalotina) e o trimetoprim. O mecanismo de resistência desta bactéria aos $\beta$-lactâmicos é a produção de $\beta$-lactamase de amplo espectro ou induzíveis do tipo AmpC (cuja indução é provocada por cefalosporinas de $1^{\mathrm{a}} \mathrm{a} 2^{\mathrm{a}}$ geração e ampicilina) (24). A resistência ao trimetoprim é principalmente devido ao sistema de efluxo presente na membrana, que reduz a penetração do fármaco na célula bacteriana impedindo a interação com seu sítio-alvo (25).

O isolado de $P$. aeruginosa encontrado neste trabalho também foi sensível a antimicrobianos (ceftazidima, cefepima, ciprofloxacina e imipenem) geralmente utilizados no tratamento de infecções provocadas por essa bactéria. Os antibióticos mais usados para este fim são: cefalosporinas (ceftazidima, cefepima), fluorquinolonas (ciprofloxacina), polimixinas e carbapenêmicos (imipenem, meropenem) (26), sendo estes últimos, os fármacos de escolha de acordo com Ferreira e cols (2010) (24). Esses fármacos estão incluídos na lista de antibióticos utilizados nos centros de saúde da microrregião de Ouro Preto, Minas Gerais.

Os resultados obtidos no presente estudo foram relatados à direção do hospital para que outras análises fossem realizadas a fim de se encontrar subsídios e alternativas para a solução do problema, ou seja, a presença de $P$. aeruginosa em roupas já lavadas. Neste caso, aconselha-se a reavaliação do protocolo utilizado para a lavagem das roupas, incluindo agentes desinfetantes e temperatura de lavagem.

Diante da evidência da possibilidade de disseminação de microrganismos e as condições de saúde fragilizadas de pacientes hospitalizados, sugere-se também a avaliação e o monitoramento do estado geral de higiene da área limpa da lavanderia: superfícies de equipamentos e prateleiras de estoque, mãos dos funcionários e do ar ambiente que constituem fontes de recontaminação das roupas limpas após desinfecção dos processos de lavagem (27).

\section{CONCLUSÃO}

Esse estudo possibilitou a análise da qualidade da água do centro de saúde em questão com a deteç̧ão de $P$. aeruginosa na água de enxague da roupa limpa. $\mathrm{O}$ resultado aponta para o problema de contaminação de roupas que pode ser fonte de infecções hospitalares. Além disso, esse estudo é importante para incentivar as instituições de saúde a estabelerem protocolos de avaliações periódicas da qualidade microbiológica da água, como também dos processos utilizados para higienização de roupas hospitalares e também incentivar instituições acadêmicas a realizarem esse tipo de estudo visando auxiliar centros de saúde e assim minimizar possíveis focos de contaminação.

\section{AGRADECIMENTOS}

Ao Programa de Educação Tutorial (PET), ao Ministério da Educação pelo apoio e colaboração, ao Centro de Sáude que forneceu as amostras de estudo para realização deste trabalho. 


\section{REFERÊNCIAS}

1. Andrade D, Angerami ELS, Padovani CR. Condição microbiológica dos leitos hospitalares antes e depois de sua limpeza. Rev Saúde Pública 2000; 34(2):163-169. DOI: 10.1590/S0034-89102000000200010

2 Sader HS, Gales AC, Pfaller MA, Mendes RE, Zoccoli $\mathrm{C}$, Barth A, Jones RN. Pathogen frequency and resistance patterns in brazilian hospitals: summary of results from three years of the SENTRY antimicrobial surveillance program. Braz J Infect Dis 2001; 5(4):200-14. DOI: 10.1590/S1413-86702001000400006

3. BRASIL. Ministério da Saúde. Portaria 1469, de 29 de dezembro de 2000. Estabelece os procedimentos e responsabilidades relativos ao controle e vigilância da qualidade da água para consumo humano e seu padrão de potabilidade, e dá outras providências. Diário Oficial da União 2001, 19 jan.

4. Silva AO, Alvarenga J, Guedes MRA, Firmino R, Pereira CAS. Pesquisa de bacilos Gram negativos não fermentadores no interior do corpo de torneiras em hospital privado. RBAC 2016; 48(1):74-77.

5. Freitas MP, Blaskowski MMM, Dalke CR, Dalzoto PR, Pimentel IC. Persistence of total and fecal coliforms and Pseudomonas aeruginosa in natura water samples from rivers that supply a water treatment station in Curitiba, Brazil. Estud Biol 2008; 30(70):63-69.

6. APHA. American Public Health Association. Standard Methods for The Examination of Water and Wastewater. 22 ed. Washington: APHA, 2012.

7. BRASIL. Ministério da Saúde. Portaria 2.914, de 12 de dezembro de 2011. Dispõe sobre os procedimentos de controle e de vigilância da qualidade da água para consumo humano e seu padrão de potabilidade. Diário Oficial da União 2011, 14 dez.

8. Medeiros LV, Vasconcelos U, Calazans GMT. Ocorrência de linhagens de Pseudomonas aeruginosa cloro resistentes em águas de diferentes origens. Acta Sci Biol Sci 2007; 29(3): 309-313. DOI: 10.4025/actascibiolsci. v29i3.488

9. Wallet F, Loïez C, Renaux E, Lemaitre N, Courcol RJ. Performances of VITEK 2 Colorimetric Cards for Identification of Gram-Positive and Gram-Negative Bacteria. J Clin Microbiol 2005; 43(9):4402-4406. DOI: 10.1128/ JCM.43.9.4402-4406.2005
10. CLSI. Performance Standards for Antimicrobial Disk Susceptibility Tests; Approved Standard-Eleventh Edition. CLSI document M02-A11. Wayne, PA: Clinical and Laboratory Standards Institute 2012.

11. CLSI. Performance Standards for Antimicrobial Disk Susceptibility Tests; Twenty-Second Information Supplement. CLSI document M100-S22. Wayne, PA: Clinical and Laboratory Standards Institute 2012.

12. Fontoura R, Spada JC, Silveira ST, Tsai SM, Brandelli A. Purification and characterization of an antimicrobial peptide produced by Pseudomonas sp. strain 4B. World J Microbiol Biotechnol 2009; 25:205-213. DOI: 10.1007/s 11274-008-9882-4

13. BRASIL. Congresso Nacional. Lei $\mathrm{n}^{\circ}$ 9.431, de 6 de janeiro de 1997. Dispõe sobre a obrigatoriedade da manutenção de programa de controle de infecções hospitalares pelos hospitais do País. Diário Oficial da União 1997,6 jan.

14. Dias RS, Santos DN, Fernandes TMG, Ferreira JGG. Infecção hospitalar - IH - causas múltiplas e fatores de risco associados a microrganismos de veiculação hídrica. Rev Tecer 2008; 1(1):54-60.

15. Fijan S, Koren S, Cencic A, Sostar-Turk S. Antimicrobial disinfection effect of a laundering procedure for hospital textiles against various indicator bacteria and fungi using different substrates for simulating human excrements. Diagn Microbiol Infect Dis 2007; 57(3):251-57. DOI: 10.1016/j.diagmicrobio.2006.08.020

16. Barrie D, Hoffman PN, Wilson JA, Kramer JM. Contamination of hospital linen by Bacillus cereus. Epidemiol Infect 1994; 113(2):297-306. DOI: 10.1017/ S0950268800051724.

17. Kirby WMM, Corpron DO. Urinary tract infections caused by antibiotic-resistant coliform bacilli. J Am Med Assoc 1956; 162(1):1-4.

18. Brunton WA. Infection and hospital laundry. Lancet 1995; 345:1574. DOI: 10.1016/S0140-6736(95)91124-3

19. Wilcox MH, Jones BL. Enterococci and hospital laundry. Lancet 1995; 345:594. DOI: 10.1016/S01406736(95)90507-3

20. Torres JCN, Menezes EA, Ângelo MRF, Olviveira IRN, Salviano MNC, Xavier DE, Filho LS. Cepas de Pseudo- 


\section{Anganana}

monas spp. produtoras de metalo- betalactamase isoladas no Hospital Geral de Fortaleza. Bras Patol Med Lab 2006; 42(1):313-9. DOI:10.1590/S1676-24442006000500003

21. Blot S, Vandewoude K, Hoste E, Colardyn F. Reappraisal of attributable mortality in critically ill patients with nosocomial bacteraemia involving Pseudomonas aeruginosa. J Hospital Infection 2003; 53(1):18-24. DOI: 10.1053/jhin.2002.1329

22. Freitas VR, Sand TSVD, Simonetti AB. Formação in vitro de biofilme por Pseudomonas aeruginosa e Staphylococcus aureus na superfície de canetas odontológicas de alta rotação. Rev Odontol UNESP 2010; 39(4):193-200.

23. Fux CA, Costerton JW, Stewart PS, Stoodley P. Survival strategies of infectious biofilms. Trends Microbiol 2005; 13(1):34-40. DOI: 10.1016/j.tim.2004.11.010
24. Ferreira H, Lala ERP. Pseudomonas aeruginosa: Um alerta aos profissionais de saúde. Rev Panam Infectol 2010; 12(2):44-50.

25. Hancock REW, Speert DP. Antibiotic resistance in Pseudomonas aeruginosa: mechanisms and impact on treatment. Drug Resist Updat 2000; 3(4):247-255. DOI: 10.1054/drup.2000.0152

26. Paviani ER, Stadnik CB, Heinek I. Estudo da epidemiologia e perfil de sensibilidade da Pseudomonas aeruginosa. Infarma 2004; 15(11-12):66-70.

27. Fijan S, Sostar-Turk S, Cencic A. Implementing hygiene monitoring systems in hospital laundries in order to reduce microbial contamination of hospital textiles. J Hosp Infect 2005; 61(1):30-8. DOI: 10.1016/j. jhin.2005.02.0052005. 